ruptured tubal pregnancy, leaving the surrounding parts in such condition that he permanently closes the latter incision without drainage. with through-and-through silk-worm gut sutures, reinforced by buried kangaroo tendons, through the peritoneai parts, and within ten days therearter, preceded by great abdominal pains, pus forces its way through the first incision in such quantities that a cotton pad one inch thick, by eight inches square, is to half its extent, twice a day saturated thereby, and such pus, without diminution, continues to discharge for the period of ninety days, to what would you, as a physician and surgeon, attribute the origin of such pus?

What would you do under such circumstances?

If the same conditions continued for four months, to what would you attribute the origin of such pus? What would you do, etc.?

If the same conditions existed for six months, to what would you attribute the origin of said pus? What would you do etc.?

If the same conditions existed for nine months, to what would you attribute the origin of said pus? What would you do, etc.?

If the same conditions existed for twelve months, to what would you attribute the origin of said pus? What would you do, etc.?

If, after eighteen (18) months, the same conditions, having continued to exist, the said first incision being opened up, and there should be found in the abdominal cavity, a cheesecloth sponge, composed of eight layers of checse-cloth $21 \% \mathrm{x} 3$ inches in size, saturated by pus, and the same had been in said cavity from the time of the first incision. to what would you attribute the origin of said pus, so discharging during said eighteen months?

The grounds for the suit as alleged by the plaintiff are sufficiently well outlined by the questions. The legal points which the plaintiff undertook to prove were lack of ordinary care and skill in making the operation, and inattention, neglect, and lack of ordinary skill in the care of the patient after the operation.

Medical experts were examined on the steps of an ordinarily skilful operation, the amount of pus which an infected kangaroo tendon would or could cause to be secreted but the question which caused experts the most trouble, was to fix a time after an operation where, if conditions as mentioned in the hypothetical question had supervened, they would cease to wait for nature to right the trouble, and whey would seek to do so by surgical means. The examination of one expert elicited the fact that he himself had in one instance waited for six years for nature to discharge a suture which he had introduced during the operation. Only the experts for the plaintiff were heard, as at the close of the plaintiff's evidence the defendant moved to dismiss the case because the statute limitation had expired before the proceeding had been begun, and the court so held.

One of the most powerful influences, because the most subtle, which leads to the physician's decision in such a case is a purely psychologic one, and one which he ought always to be on the lookout for. There can be no question that a physician will, with less personal disquiet, invoke surgical influences in such a case as the above, if it be referred to him, than in a case of his own. And where a physician's desire is strong in a given direction, it is astonishing how that desire will cover up unwelcome symptoms, and how it will exaggerate the diagnostic and prognostic value of intercurrent and unimportant ones.

The case is to be carried up on error.

JAMes L. Tracy.

\section{Value of the Medical Visit.}

St. Lovis, June 14, 1900.

To the Editor:-The following is one of many letters which I have received since the publication of my communication on "The Value of the Medical Visit" in The Journal of June 2. (p. 1430) :

\section{H. Hughes, M.D. :}

ToLedo, June 7, 1900.

ST. LouIs, Mo.:

My Dear Doctor:-Kindly tell me if you ever knew a physieian who did or could carry into practice the very truthful propositions of what ought to be done, as outlined in your etter in THe Joursal.

I believe it is a fact that, in this city, a recent graduate is more likely to demand a good fee than is the man whose long experience should entitle him to it, and I think that the universal practice is to charge one price for a visit.

Respectfully,

Replying to this and many other letters. I would say that I always estimate a visit according to what I do for the patient; aceording to the time spent with him and lost from my office or hours of study and investigation; according to the time passed since I graduated; according to the ability or nonability to compensate for full value of service; according to special manipulative and technical skill demanded and the value of advice given, as growing out of the facts learned and the skill and experience possessed.

For all to charge one price for a visit is to rob experience of its due value, and younger medical men of legitimate opportunity in practice. C. H. HUGHES, M.D.

\section{Medical Transactions.}

HARTFORD, ConN., June 16, I900.

To the Editor:-Volumes of transactions of medical societies are very often disappointing to the reader. It is a question whether the publication of such volumes has more than a mere local interest. The criticism of ten made of the papers of the American Mrdical Association is that they have only a personal and local interest, and rarely rise to the height of being real contributions to the literature of the subject. This was true in some cases years ago, but there has been a gradual and woll-marked improvement since THE Journal began to publish these papers. Each year's transactions show a larger proportion of well-rounded, thoroughlystudied papers, and this is the secret of the increasing respect which the Association is receiving in all quarters. State and local associations, whose published volumes of transactions are increasing rapidly year after year, have a local interest which should be encouraged. While many of them are but little above the ordinary journal in their ephemeral character, their value undoubtedly is more to the author than to the reader. As studies of psychology and the growth of medical thought and practice, they are excedingly interesting.

A study of the transactions of different states is very interesting and is probably on a par with the sermons of the divines of a hundred years ago. Papers read in these local and state societies, when confined to epidemies and discussion of local conditions falling under the observation of the author, have great value, but when the author goes out.into the field of medicine, discusses larger topics and draws weighty conclusions concerning scientific theories and movements, the value of his contribution is lost. The most valuable papers ever presented to the Aurerican Medical Association were local personal studies of diseases and methods of treatment which the author had discovered and tested in his experience. If they were extreme and unsupported by other deductions, or contrary to the present experience, the test of time always brought them into prominence or forgetfulness. An author who gives his personal experience, with the facts on which it is based, no matter what transactions it may be published in, is sure of recognition if his conclusions are correct.

The value of these local transactions is more largely in the culture and practice which it brings to the author in putting his ideas into print. Until recently papers of this class were almost the only biographical data which could be found regarding physicians at death. A recent critic has very severely commented on the uselessness of many of these volumes of state and society transactions. This is only partially true, for while it may have only slight value outside of the vicinity, it certainly is worth the publication and the effort to perpetuate it. The same critic has found in volumes of transactions of societies of specialists a dreary waste of words and unfounded theories. This is also an error, although some articles written by specialists abound in technical terms in such a profusion as to indicate darkening counsel with words. A few text-books are marred by this defect. The reader is obliged to get down a modern dictionary to follow the author, 
and when, with great labor, he has discovered the meaning, it is trivial and unimportant.

The literature of medicine has attained such proportions that it attracts an army of writers who seek to appear on the printed page rather than to become instructors or teachers of new facts. Our Association meetings are gradually drawing the lines, trying to eliminate writers who have nothing to say and writers who serve up old theories without the flavor of novelty or personality. This is being accomplished in the Sections very largely. Better papers are called for, and shorter time is given, forcing the writer to condense what he has to say, to the great satisfaction of the listener. At the International Congresses at Moscow, and elsewhere, this great defect of inferior papers bids fair to destroy their usefulness. At Paris an effort will be made to check this in some measure, but the difficulty is very great. Large numbers of men will insist on reading papers that contain no new facts, to the disgust of those who have real contributions. At the meeting at Atlantic City, the officers of several sections made strenuous efforts to raise the grade of the papers offered and to keep out old discussions of common-place subjects unless by men of acknowledged ability. Authors of papers should never forget that the scope of the American Medicar Association is far broader than that of little sectional gatherings.

Through the columns ofThE Journat, papers come before thousands of the best men in the profession, and unless these authors have something to say and say it briefly and clearly, their efforts will be unnoticed. In a local medical society or in a state society the personality of essilyists will attract readers and attention, and the transactions in which these papers are published will keep up a personal interest not noticed otherwise. It is an error to suppose that a paper which is praised at the local society will receive equal praise when brought before the general profession. Many a man has become disgusted at not receiving the attention for his contribution before the American Medical Association which was granted to him by his local society, and has attributed it to jealously and ring rule. Many of the bitter enemies of our Association have become deluded with this idea and have become bitter detractors. Notwithstanding this, the AssoctaTION goes on, aiming to be national in its efforts and work, and broad and catholic in its recognition of scientific facts everywhere. The seeker for mutual admiration and the mutual admiration society should confine his efforts to his local society and live in its transactions.

T. D. CRothers, M.D.

\section{Book 2Totices.}

Diseases of the Gall-Bladder and Bile-Ducts, Including Gall-Stones. By A. W. Mayo Robson, F.R.C.S., Senior Sur. geon to the General Infirmary at Leeds, assisted by Farquhar Macrae, M.B., C.M. (Glas.). Second Edition. Cloth. Pp. 313. Price, \$3. New York: William Wood \& Co. 1900.

This second edition of Mayo Robson's lectures on "Diseases of the Gall-Bladder and Bile-Ducts" contains, in addition to the former contents, chapters on Membranous Cholecystitis and on Gall-Stones, and numerous additions thoroughout the text. The cases have been classified, instead of being all grouped together at the end of the work, of which they take up about one-fourth or one-third in tabulated form. The series illustrates the advance that has been made in the surgery of this region, and the much more favorable results of late years.

Diseases of the Nose and Throat. By J. Price-Brown, M.B., L.R.C.P.E., Member of the College of Physicians and Surgeons of Ontario; Laryngologist to the Toronto Western Hospital; Laryngologist to the Protestant Orphans' Home; Fellow of the American Laryngological, Rhinological, and Otological Society; Member of the British Medical Association, the Pan-American Medical Congress, the Canadian Medical Association, the Ontario Medieal Association, Etc. Illustrated with 159 Engavings, including 6 Full-Page Colorplates and 9 Color-cutes in the text. Cloth. Pp. 470. Price, \$3.50. Philadelphia: The F. A. Davis Co. 1900.

This handsome volume, by a prominent Canadian physician, is a very valuable addition to the literature of diseases of the nose and throat. The author has given the results of his experience, as a specialist and general practitioner, with these affections, in a practical way that can not but be of value to the student and practicing physician. Certain subjects which are generally included are omitted, for reasons stated by the author in his preface. Aural affections, for example, which are usually included with diseases of the nose and throat, are only incidentally touched upon, and the subject of diphtheria is entirely left aside. The only omissions, however, which might have been better avoided are some slight ones in regard to special points, such, for example, as the use of suprarenal extract. which certainly has a place in works on nose and throat diseases, but which we do not here find alluded to. It it not a work to post a person fully on the subject if we give it its usual limits, but so far as it goes it is a most valuable addition to the literature.

The Irrigation Treatment of Gonorriea: Its Local Complications and Sequele. By Ferd C. Valentine, M.D., Professor of Genito-Urinary Diseases, New York School of Medicine. Illustrated by fifty-seven engravings. Cloth. Pp. 221, Price, \$2. New York: William Wood \& Co. 1900.

The object of this work, according to the author's statement at the close, is to "place before those physicians who may not be thoroughly familiar therewith:

1. The rationale and technique of irrigations in acute gonorrhea.

2. The advantages of dilatations and irrigations in chronic gonorrhea.

3 . The dangers of uncured gonorrhea, and the means of locating the foci of the disease, especially after its external manifestations have subsided.

4. To urge physicians to use their influence for the dissemination of a better understanding of the disease.

Comparatively few text-books treat of this special therapeutic method in this disease, the importance of which has only of late been fully appreciated. As the book is intended for the general practitioner, to whom it is dedicated by the author, it will, without doubt, fill a very useful place in medical literature. It is clearly written, very fully illustrated, and covers the subject in an exhaustive way. We trust the general practitioner will appreciate and utilize it.

Home Nursing. Modern Sclentific Methods for the Care of THE SICK. By Eveleen Harrison. Cloth. Pp. 325. Price, \$1. New York: The Macmillan Co. London: Macmillan \& Co.s Itd. 1900.

This little work contains a description of the general prineiples and methods of nursing as applied to the home care of the sick, and, therefore, ought to serve a very useful purpose. There are many cases, as the author says, where the trained nurse is not really required, and many others where the expense is an unsurmountable bar to her employment, and it is for such cases as these that the book is designed. So far as we can see, it contains a very valuable amount of information excellently given, and can not help but be of service. There are one or two cases where we might take exception. It is possible that some of the directions in regard to poisoning are too general. In the main, however, the author is safe in her recommendations, and the book can be most heartily indorsed, as a whole, for the purpose for which it is intended.

Serumtherapy. Published by the Scientific Department of

Frederick Stearns \& Co., Detroit, Mich.

This brochure of fifty pages contains matter of interest re garding serumtherapy, how antitoxin serums are produced, directions for the collection and transmission of specimens of sputum, etc., for bacteriologic examinations, and other valuable information.

Anesthetics: Their Uses and Administration. By Dudley Wilmot Buxton, M.D., B.S., Member of the Royal College of Physicians. Third Edition. Cloth. Pp. 320. Price, \$1.50. London: H. K. Lewis. Philadelphia: P. Blakiston's Son \& Co. 1900.

This volume is the third edition of a comparatively wellknown English work, which has been out of print some time, revised and brought up to date. The main additions are descriptions of methods of giving nitrous oxid in combination with oxygen, ether in combination with oxygen, Dr. Flux's open method of giving nitrous oxid, Schleich's methods of local 